\title{
Hydrogen Oxidation and Hydrogen Evolution on a Platinum Electrode in Acetonitrile
}

\author{
Isis Ledezma-Yanez, Oscar Díaz-Morales, Marta C. Figueiredo, and Marc T. M. Koper*[a]
}

\begin{abstract}
This work discusses the kinetics of the hydrogen oxidation reaction (HOR) and hydrogen evolution reaction (HER) on a polycrystalline platinum electrode in acetonitrile, in presence of two different electrolytes. Our findings indicate the sensitivity of the kinetics of these reactions to the presence of small amounts of water. In situ FTIR spectroscopy reveals the ion migration owing to the preferential solvation of protons by residual water, whereas surface-enhanced Raman spectroscopy con-
\end{abstract}

firms that the water leaves the interface under hydrogen oxidation conditions. These observations imply that the kinetic sensitivity of this electrocatalytic reaction towards the preferential solvation processes presents a serious constraint in the establishment of a reference electrode for nonaqueous solvents based on HOR/HER on platinum, and on the comparison of its catalysis in various nonaqueous solvents.

\section{Introduction}

The hydrogen oxidation reaction (HOR) and hydrogen evolution reaction (HER) are key reactions in electrochemistry, ${ }^{[1]}$ as well as in the development of technologies towards clean energy and fuel cells. The majority of electrochemical studies on HOR/HER have pertained to aqueous electrolytes. With the search for new, cheap, and efficient catalysts for HER, studies of molecular catalysts often employ nonaqueous solvents, such as acetonitrile, for activity testing. ${ }^{[2]}$ Having a standard activity test in the same solvent then becomes desirable, including detailed insight into the molecular mechanisms involved in this standard system. Platinum would be the most suitable electrode material for such a benchmark activity test, as it is for tests in aqueous electrolytes. Although several studies on the HER and HOR in acetonitrile ${ }^{[3]}$ have been carried out, comparatively little has been settled about the mechanism involved, such as the role of cations, anions and residual water, leading to an incomplete understanding of the process and its catalysis.

Acetonitrile is an aprotic solvent that has proved to be convenient for use in electrochemistry, ${ }^{[4]}$ primarily related to its miscibility with water, combined with a relatively high dielectric constant (37.5), giving excellent solvation properties for a variety of electrolytes. However, ion pairs can form in acetonitrile $^{[5]}$ and, under certain conditions, the solvent can also adsorb strongly or even dissociate on the electrode surface ${ }^{[6]}$ under the influence of an electrode potential. These features make acetonitrile especially sensitive to the use of different

[a] I. Ledezma-Yanez, O. Díaz-Morales, Dr. M. C. Figueiredo, Prof. M. T. M. Koper Leiden Institute of Chemistry, Leiden University

PO Box 9502, 2300 RA Leiden (The Netherlands) E-mail:m.koper@chem.leidenuniv.nl

$\square$ Supporting Information for this article is available on the WWW under http://dx.doi.org/10.1002/celc.201500341.

An invited contribution to a Special Issue on In Situ Monitoring of Fuel Cell and Battery Processes supporting electrolytes for hydrogen oxidation and evolution, leading to voltammetric responses that have proved difficult to interpret.

Early work by Lanning and Chambers ${ }^{[1 f]}$ as well as Barrette and Sawyer ${ }^{[7]}$ demonstrated the high sensitivity to, and even irreproducibility of, electrolyte parameters of HER and HOR activity on a platinum electrode in acetonitrile. More recent findings reported by Suárez-Herrera et al. ${ }^{[3 c]}$ highlighted the role of the nature of cations and the presence of water on the HOR activity on single-crystal platinum electrodes in acetonitrile. In situ infrared data revealed that chemisorption of hydrogen, acetonitrile, and cyanide only takes place when water is present at the interface. Interestingly, they propose that hydrogen oxidation on platinum in acetonitrile is mediated by hydroxyl groups present on the electrode surface, as formed by the oxidation of residual water. According to their results, the proton released in this process is stabilized by forming an ion pair with the electrolyte anion. This proposition is in agreement with the earlier observation that oxidation of Pt activates the surface for the HOR in acetonitrile. ${ }^{[7]}$ Those conclusions lead us to the intriguing apparent paradox that, in acetonitrile, HOR takes place on an oxygen-covered Pt surface, whereas in aqueous electrolyte, HOR takes place on a hydrogen-covered Pt surface. ${ }^{[8]}$ It also raises the question whether $\mathrm{Pt}$ is really a suitable activity standard for HOR/HER in acetonitrile.

In this work, we present a combined electrochemical and in situ spectroscopic studies of the HOR/HER on platinum in acetonitrile. We aim to understand 1) how the interaction of acetonitrile with the electrolyte ions and with platinum ${ }^{[6,9]}$ affects the catalytic activity, and 2) how a small amount of water interferes with catalytic activity in the presence of two different cations, that is, tetrabutylammonium $\mathrm{TBA}^{+}$and lithium $\mathrm{Li}^{+}$, expecting the latter to have a stronger specific interaction with water. Our results show that the HOR/HER on Pt involves a reversible process in acetonitrile, but also that there is a crucial 
role of water and cations. According to our findings, the role of water seems to be primarily in the preferential solvation of protons and other small cations, rather than in the activation of the platinum surface.

\section{Results and Discussion}

\subsection{Reference Scale: From $\mathrm{Ag}^{\circ} / \mathrm{Ag}^{+}$to $\mathrm{SHE}$}

In this work, we employ a practical reference scale suitable for the $\mathrm{H}^{+} / \mathrm{H}_{2}$ couple in acetonitrile. Fourmond et al. ${ }^{[2 \mathrm{~d}]}$ have recently reconsidered the standard potential of the hydrogen couple in acetonitrile, $E_{\mathrm{SHE}}^{\mathrm{MeCN}}$, measured by using a molecular catalyst, and reported an estimated value of $-0.070 \mathrm{~V}$ versus $\mathrm{Fc}^{0} / \mathrm{Fc}^{+}$, which corresponds to $-0.033 \mathrm{~V}$ versus our $\mathrm{Ag} / \mathrm{AgClO}_{4}$ electrode in acetonitrile. However, standard conditions are generally not achievable, owing to the low dissociation constant of acids in organic solvents, including perchloric acid in acetonitrile $\left(p k_{\mathrm{a}}=1.57\right)$; therefore [Eqs. (1) and (2)]:[10]

$$
\begin{aligned}
& E_{\mathrm{H}^{+} / \mathrm{H}_{2}}^{\mathrm{eq}, \mathrm{MeCN}}=E_{\mathrm{H}^{+} / \mathrm{H}_{2}}^{0, \mathrm{MeCN}}+\frac{R T}{2 F} \ln \frac{\left[\mathrm{H}^{+}\right]^{2}}{p\left(\mathrm{H}_{2}\right)} \\
& E_{\mathrm{H}^{+} / \mathrm{H}_{2}}^{\mathrm{eq} \mathrm{MeCN}}=E_{\mathrm{SHE}}^{\mathrm{MeCN}}+\frac{R T}{2 F} \ln \frac{(\alpha C)^{2}}{p\left(\mathrm{H}_{2}\right)}
\end{aligned}
$$

where $\alpha$ is the degree of dissociation and $c$ is the nominal concentration of the HA acid (all other parameters have their standard meanings).

We note that there is still considerable uncertainty in the "real" value of $E_{\mathrm{SHE}}^{\mathrm{MeCN}}$. The estimated value quoted by Fourmond et al. deviates from previous values, and is also approximately $0.1-0.2 \mathrm{~V}$ different from theoretical estimates by Fawcett. ${ }^{[11]}$ In the voltammetric curves shown below, $\mathrm{V}_{\mathrm{SHE}}$ is understood as the electrode potential referred to $E_{\mathrm{SHE}}^{\mathrm{MeCN}}$.

\subsection{Voltammetry for HOR/HER in Acetonitrile}

Figures 1 and 2 show the cyclic voltammograms for polycrystalline platinum in acetonitrile, using tetrabutylammonium perchlorate (TBAP; black solid line) or $\mathrm{LiClO}_{4}$ (red dashed line) as supporting electrolytes. Figure 1 a shows the hydrogen oxidation in the base electrolyte in the absence of a proton donor. Figure $1 \mathrm{~b}$ shows the hydrogen evolution in the presence of $10 \mathrm{mM} \mathrm{HClO}_{4}$ in an Ar-saturated electrolyte. Finally, Figure $1 \mathrm{c}$ combines the HOR and the HER in the presence of $10 \mathrm{~mm}$ $\mathrm{HClO}_{4}$ in a $\mathrm{H}_{2}$-saturated electrolyte. In each subfigure (a-c), we present the last cycle out of 200 scans between 1.0 and $-1.0 \mathrm{~V}_{\mathrm{SHE}}$, starting the sweep at $0.1 \mathrm{~V}_{\mathrm{SHE}}$ in the cathodic direction. The blank voltammetry of $\mathrm{Pt}$ in both electrolytes is rather featureless and is shown in Figure S1 in the Supporting Information. In both electrolytes, there is a pair of reduction/oxidation peaks that is clearly observed in the first scan, but disappears quickly in subsequent scans. HER/HOR currents are sensitive to the scan rate in both electrolytes (Figure S2). In particular, the HOR current decreases at lower scan rates, whereas the system with TBAP exhibits a larger HER current in the acidic solution. In general, the HER/HOR becomes more reversible at

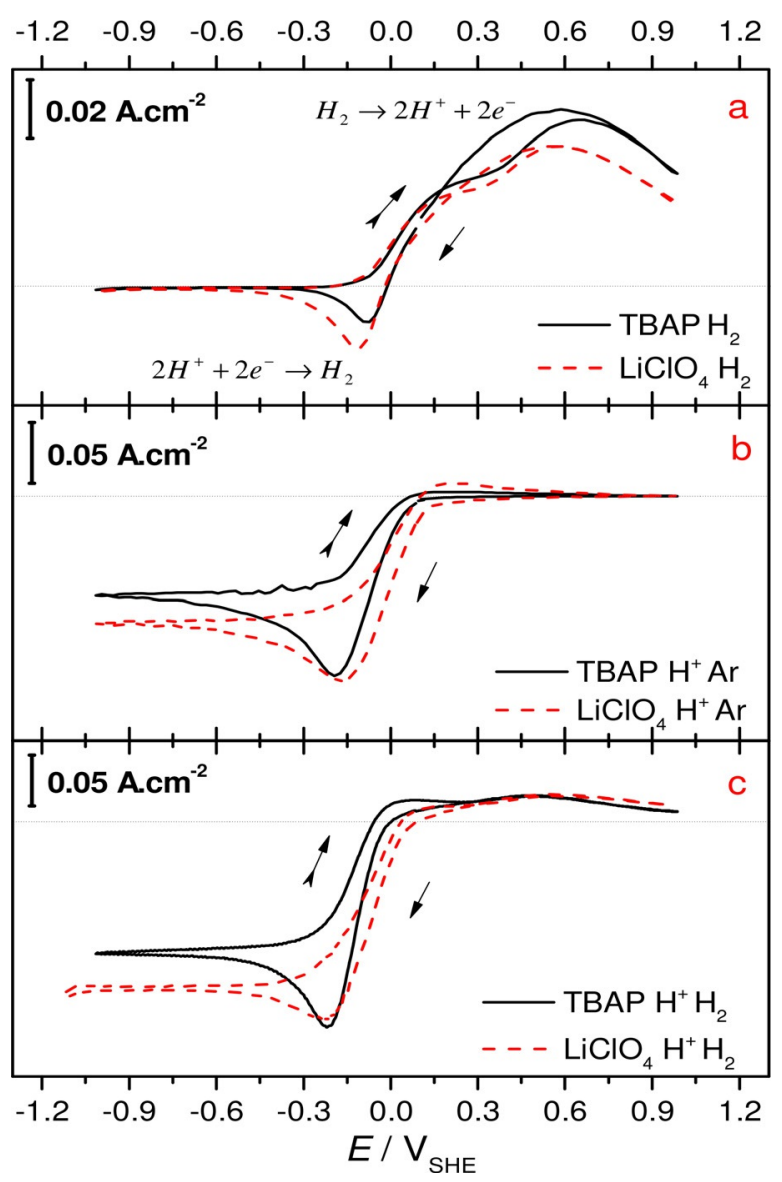

Figure 1. Cyclic voltammograms for a polycrystalline platinum wire in acetonitrile containing $100 \mathrm{~mm} \mathrm{LiClO}_{4}$ (red dashed line) or $100 \mathrm{~mm}$ TBAP (black solid line) as supporting electrolytes: a) hydrogen saturated; b) after adding $10 \mathrm{~mm} \mathrm{HClO}_{4}$, argon saturated; c) after adding $10 \mathrm{~mm} \mathrm{HClO}_{4}$, hydrogen saturated. Scan rate: $500 \mathrm{mVs}^{-1}$, in order to minimize gradual solvent decomposition. ${ }^{[12]}$ The horizontal dotted lines mark zero current.

high scan rates for both electrolytes, suggesting the presence of a slow deactivation process in the system.

Figure 1 a shows the voltammetry recorded for the solution saturated with hydrogen, with the peak for hydrogen oxidation presenting a similar current and shape for both electrolytes. In the negative-going scan, a proton reduction peak is observed, which is somewhat larger for the $\mathrm{LiClO}_{4}$ electrolyte. In Figure $1 \mathrm{~b}$, the voltammetry for solutions containing $10 \mathrm{~mm} \mathrm{HClO}_{4}$ for each electrolyte, saturated with $\mathrm{Ar}$, should have a real proton concentration of $2.1 \mathrm{~mm}$, as calculated from the $\mathrm{p} K_{\mathrm{a}}$ of the acid. Clearly, the proton reduction peak in Figure $1 \mathrm{~b}$ has a higher current compared to the same peak in Figure $1 \mathrm{a}$. A small current is observed in the positive-going scan, corresponding to the oxidation of $\mathrm{H}_{2}$ formed in the previous cathodic scan. Evaluation of the HER/HOR couple in Figure $1 \mathrm{c}$ shows a similarly shaped proton reduction peak in comparison with Figure $1 \mathrm{~b}$ (though the current is slightly larger in Figure $1 \mathrm{c}$, owing to proton formation in the oxidation of molecular hydrogen). However, the HOR current is considerably smaller than in the proton-free electrolyte solution depicted in Figure $1 \mathrm{a}$. 


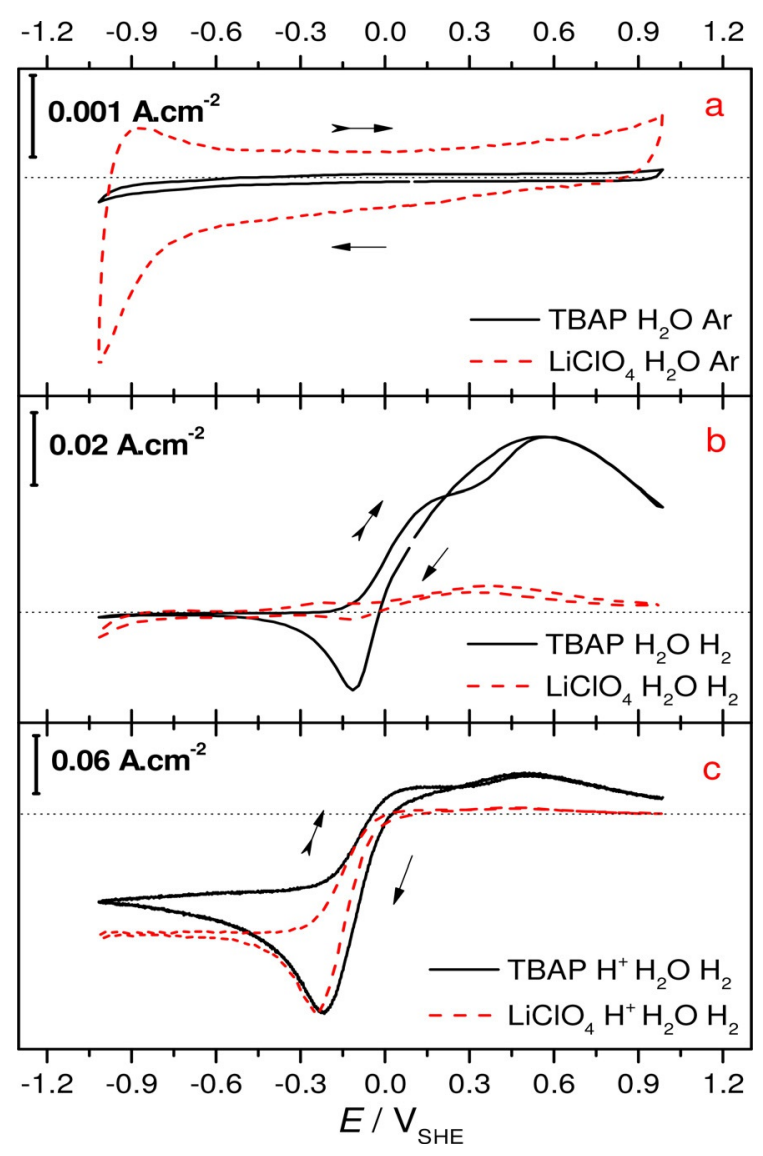

Figure 2. Cyclic voltammograms for a polycrystalline platinum wire in acetonitrile containing $100 \mathrm{~mm} \mathrm{LiClO}_{4}$ (red dashed line) or $100 \mathrm{~mm}$ TBAP (black solid line) as supporting electrolytes, in the presence of $50 \mathrm{~mm} \mathrm{H}_{2} \mathrm{O}$ : a) argon saturated; b) hydrogen saturated; c) sdding $10 \mathrm{~mm} \mathrm{HClO}_{4}$, hydrogen saturated. Scan rate: $500 \mathrm{mV} \mathrm{s}^{-1}$. The horizontal dotted lines mark zero current.

Figure 2 shows the cyclic voltammetry for polycrystalline platinum in acetonitrile, using TBAP (black solid line) or $\mathrm{LiClO}_{4}$ (red dashed line) as supporting electrolytes, in the presence of $50 \mathrm{~mm} \mathrm{H}_{2} \mathrm{O}$. Figure 2 a compares the blank voltammograms for both electrolytes, showing that the background current for the solution with $\mathrm{LiClO}_{4}$ is one order of magnitude larger compared with the solution containing TBAP. For the $\mathrm{LiClO}_{4}$ electrolyte, the onset potential for water reduction is approximately $-0.750 \mathrm{~V}_{\mathrm{SHE}}$ (see Figure S1a). In the anodic sweep, there is a corresponding oxidation peak, which, however, cannot be attributed to hydrogen oxidation, as that is expected to occur only at much more positive potentials (see Figure $1 \mathrm{a}$ ). For the TBAP electrolyte, no significant water reduction current is observed in this potential window. After saturating the solutions with hydrogen, Figure $2 \mathrm{~b}$ depicts the HOR process in the presence of water. The voltammetry obtained for TBAP electrolyte is very similar to the voltammetry presented in Figure $1 \mathrm{a}$ for the HOR in the absence of added water; although, the hydrogen oxidation current is slightly smaller than in Figure $1 \mathrm{a}$, whereas the reduction current peak is comparatively larger. A much more significant influence of water is observed for the $\mathrm{LiClO}_{4}$ electrolyte. Figure $2 \mathrm{~b}$ shows an irreversible behavior and a much lower redox current. Addition of $10 \mathrm{mM} \mathrm{HClO}_{4}$ to the solutions with water and saturating them with hydrogen gas leads to the voltammetric responses shown in Figure $2 \mathrm{c}$. Remarkably, the proton reduction wave is very similar for both electrolytes, and is not significantly different from the system in Figure $1 c$, but the hydrogen oxidation is significantly inhibited by the combination of $\mathrm{Li}^{+}$and water.

\subsection{FTIR Spectroelectrochemistry}

\subsubsection{Transmission Spectra}

To properly evaluate the relevant interactions between solvent and other electrolyte components, we first measured the transmission spectra for acetonitrile in the presence of $\mathrm{LiClO}_{4}$ or TBAP as supporting electrolytes, in an Ar-saturated electrolyte, in an $\mathrm{H}_{2}$-saturated electrolyte, in an Ar-saturated electrolyte containing $10 \mathrm{mM} \mathrm{HClO}_{4}$, and finally in an $\mathrm{H}_{2}$-saturated electrolyte containing $10 \mathrm{mM}^{-} \mathrm{HClO}_{4}$. The results are shown in Figures 3 (for $\mathrm{LiClO}_{4}$ ) and 4 (for TBAP); these are difference spectra, that is, the spectrum for pure acetonitrile was subtracted from the electrolyte spectra. The bands identified in the spectra will be discussed according to the relevant solution components, that is, acetonitrile, perchlorate, and water, in agreement with the bands reported in the literature. ${ }^{[13]}$

Acetonitrile (AN) shows bands in the $2940-3000 \mathrm{~cm}^{-1}$ range, ascribed to the ${ }^{2}-\mathrm{CH}$ modes, $^{[14]}$ and in the $2260-2340 \mathrm{~cm}^{-1}$ range, corresponding to the $\mathrm{C}-\mathrm{N}$ bending and stretching modes. The $\mathrm{C}-\mathrm{H}$ modes are naturally more prominent in presence of TBAP, owing to the butyl chains of the TBA cation. The most remarkable difference is in the $2260-2340 \mathrm{~cm}^{-1}$ region for the two electrolytes. The spectra for the system containing $\mathrm{LiClO}_{4}$ show two clear bands pointing downwards at 2307 and $2275 \mathrm{~cm}^{-1}$, and one band pointing upwards at $2256 \mathrm{~cm}^{-1}$, which are ascribed to $\mathrm{CN}$ bending and $\mathrm{CN}$ stretching modes. These bands are essentially undisturbed by the presence of $\mathrm{H}_{2}$ and protons (or water) in the transmission spectra. On the other hand, for the solution with TBAP (Figure 4), we observe the bands in the $2260-2340 \mathrm{~cm}^{-1}$ window to point upwards in the presence of argon or molecular hydrogen. These bands present a blueshift when compared to the equivalent spectra in Figure 3. In addition, the presence of $\mathrm{HClO}_{4}$ (and water) changes the nature of these bands in TBAP.

The perchlorate ion is characterized by the $\mathrm{Cl}-\mathrm{O}$ stretching vibration around $1100 \mathrm{~cm}^{-1}$. High- and low-frequency shoulders on the main band at $1100 \mathrm{~cm}^{-1}$ have been ascribed to perchlorate involved in the formation of contact ion pairs (CIPs). Barthel and Deser have shown the existence of such ion pairs in (more concentrated) $\mathrm{LiClO}_{4}$ solutions in $\mathrm{AN}^{[13 \mathrm{a}]}$ These CIPs are attributed to interactions between perchlorate anions and the cations, surrounded by solvent molecules. The observation of a shoulder near $1130 \mathrm{~cm}^{-1}$ in the $\mathrm{LiClO}_{4}$ electrolyte confirms the existence of ion pairs in this electrolyte. In TBAP, these features are much less prominent.

Finally, water bands between 3100 and $3750 \mathrm{~cm}^{-1}(\mathrm{O}-\mathrm{H}$ stretching region) and $1550-1900 \mathrm{~cm}^{-1}$ (O-H bending region) are observed. This illustrates that we must count on the pres- 


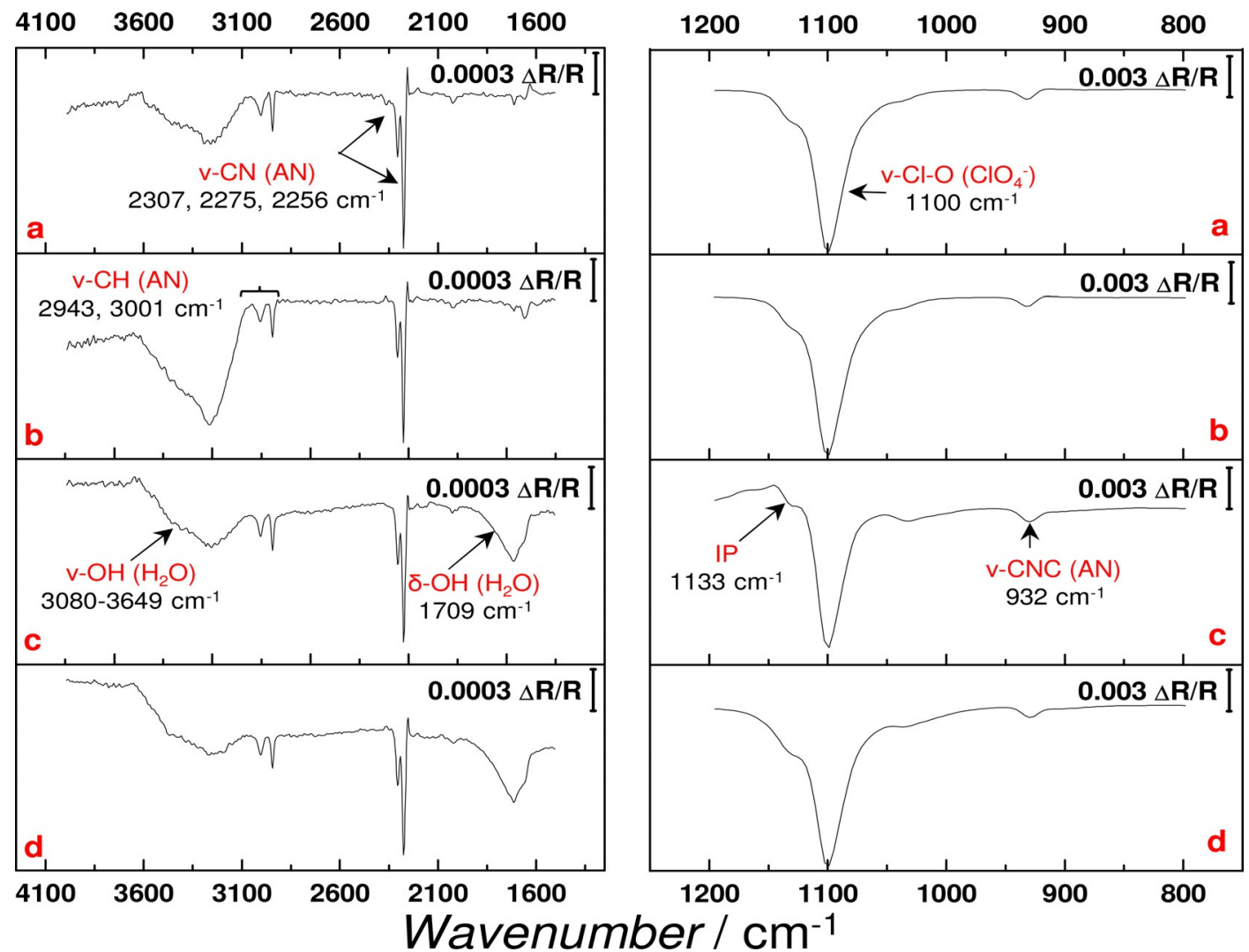

Figure 3. Transmission spectra for acetonitrile, containing $100 \mathrm{~mm} \mathrm{LiClO}_{4}$ as the supporting electrolyte: a) argon saturated; b) hydrogen saturated; c) after adding $10 \mathrm{mM} \mathrm{HClO}_{4}$, Ar saturated; d) after adding $10 \mathrm{mM} \mathrm{HClO}_{4}, \mathrm{H}_{2}$ saturated. The spectrum for pure acetonitrile was subtracted and the spectra in the figures correspond to difference spectra (IP stands for ion pairs).

ence of trace amounts of water in "dry" AN with added electrolyte, and substantial amounts of water in AN acidified with $\mathrm{HClO}_{4}$. No significant differences were observed between the blank solutions saturated with argon and those saturated with hydrogen.

\subsubsection{Substractively Normalized Interfacial FTIR Spectroscopy (SNIFTIRS)}

The potential-dependent SNIFTIR spectra for platinum in acetonitrile that contained $100 \mathrm{~mm}$ TBAP or $\mathrm{LiClO}_{4}$ under different conditions are shown in Figures 5 and 6 . The spectra were taken from negative towards positive potentials (bottom to top in each subfigure), and plotted as difference spectra, with the reference spectrum taken at $-0.314 \mathrm{~V}_{\mathrm{SHE}}$. By convention, the bands pointing upwards are ascribed as positive bands, whereas the bands pointing downwards correspond to negative bands. Some of the characteristic bands from the acetonitrile electrolyte described in the previous section are present in the spectra shown in Figures 5 and 6.

Figure 5 a (top panels) shows the spectra for the TBAP-acetonitrile electrolyte in the absence of $\mathrm{H}_{2}$ or proton donor. As depicted in the figure, the $\mathrm{C}-\mathrm{H}$ and $\mathrm{C}-\mathrm{N}$ vibrations are potential dependent, owing to a change in the orientation of the near-surface $\mathrm{AN}$ as a result of the applied potential. ${ }^{[9]}$ Under conditions of hydrogen oxidation at the platinum electrode
(Figure $5 \mathrm{~b}$, middle panels), we observe two important changes: the appearance of a positive band in the $\mathrm{O}-\mathrm{H}$ stretching region $\left(3300-3750 \mathrm{~cm}^{-1}\right)$ and $\mathrm{O}-\mathrm{H}$ bending region (tail observed at $1633 \mathrm{~cm}^{-1}$ ), indicating that water is depleting from the electrode surface; and the development of a negative band in the $\mathrm{Cl}-\mathrm{O}$ stretching region around $1130 \mathrm{~cm}^{-1}$, indicating that perchlorate anions are being attracted or migrating to the electrode surface. In the presence of $\mathrm{HClO}_{4}$, the same bands are observed. The most likely interpretation of these results is that the protons generated by $\mathrm{H}_{2}$ oxidation are preferentially solvated by water. Under oxidation conditions, these water-solvated protons move away from the surface (hence the observed depletion of water) and the perchlorate ions migrate towards the surface. No significant difference was found between the features for the system with and without acid, in presence of $\mathrm{H}_{2}$, other than that the water-related band appears at lower potentials in the presence of acid.

Figure 6 shows the FTIR spectra for platinum in acetonitrile containing $100 \mathrm{~mm} \mathrm{LiClO}_{4}$, under the same conditions as in Figure 5. Qualitatively, the spectra are similar to Figure 5, but some significant differences can be observed. In the system saturated with argon (Figure $6 \mathrm{a}$, top panels), we observe the $\mathrm{CN}$ stretching modes for acetonitrile. In presence of hydrogen (Figure $6 \mathrm{~b}$, middle panels), we observe the occurrence of a third shoulder around $3469 \mathrm{~cm}^{-1}$ in the $\mathrm{O}-\mathrm{H}$ stretching region $\left(3300-3750 \mathrm{~cm}^{-1}\right)$, which may be attributed to the interaction 


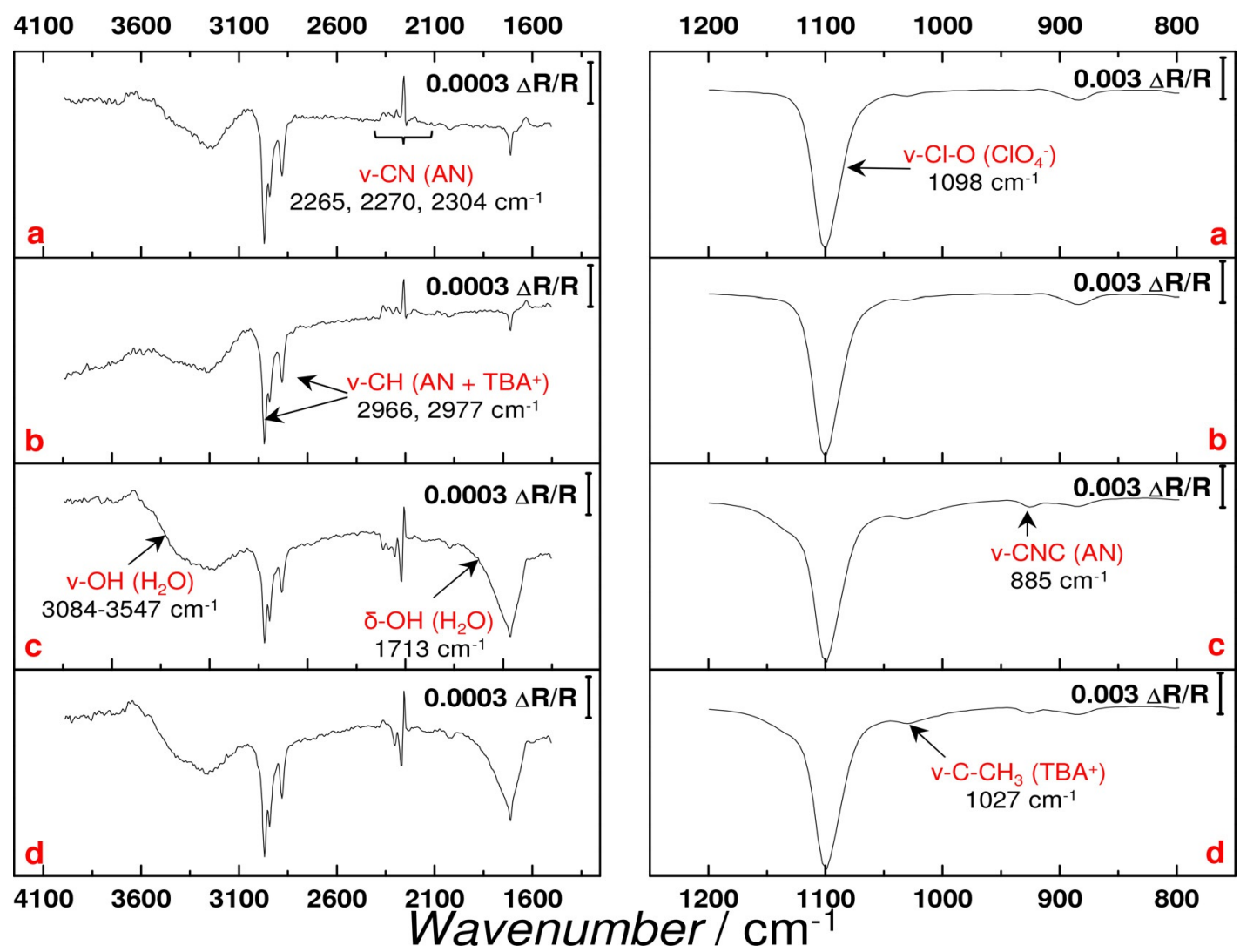

Figure 4. Transmission spectra for acetonitrile, containing $100 \mathrm{~mm}$ TBAP as the supporting electrolyte: a) argon saturated; b) hydrogen saturated; c) after adding $10 \mathrm{~mm} \mathrm{HClO}_{4}$, Ar saturated; d) after adding $10 \mathrm{~mm} \mathrm{HClO}_{4}, \mathrm{H}_{2}$ saturated. The spectrum for pure acetonitrile was subtracted and the spectra in the figures correspond to difference spectra.

of water with the $\mathrm{Li}^{+}$, as it is not observed for the systems with TBAP (compare Figure 5 and 6). These observations are complementary to the observations in Figure 5, as the lithium cation shows preferential solvation in presence of water ${ }^{[15]}$ and implies that the water is leaving the surface by solvating and migrating with $\mathrm{Li}^{+}$and the $\mathrm{H}^{+}$formed during the hydrogen oxidation.

\subsection{Surface-Enhanced Raman Spectroscopy (SERS)}

The potential-dependent SER spectra for platinum in acetonitrile containing $100 \mathrm{~mm}$ electrolyte are shown in Figures 7 and 8 (the region of $2000-2200 \mathrm{~cm}^{-1}$ ). The spectra from 100 to $2250 \mathrm{~cm}^{-1}$ are shown in Figures S3 and S4. The bands depicted here appear around 2070 and $2140-2160 \mathrm{~cm}^{-1}$ and have been reported $^{[6]}$ as the $v$-CN vibrations from isocyanide adsorbed on the surface of the electrode, that is, with $\mathrm{N}$ binding to the Pt. In agreement with the report by Tian and co-workers, ${ }^{[6]}$ this suggests that acetonitrile decomposes on the platinum surface, especially at more negative potentials (the potential window in their measurements was $0.7 \mathrm{~V}$ more negative than ours). They also observed that the presence of water inhibits the acetonitrile decomposition. Interestingly, under conditions of water removal from the surface $\left(\mathrm{H}_{2}\right.$ oxidation) at positive potential, the (iso)cyanide bands at $2050-2150 \mathrm{~cm}^{-1}$ appear. The bands are much weaker (and even absent in TBAP electro- lyte in our potential window) when no hydrogen oxidation/ proton generation takes place. This could be interpreted as a "protective layer" of water on the Pt surface under unreactive conditions, which is removed by the generation of protons that are preferentially solvated by water.

The band positions are potential dependent, as observed by Tian and co-workers, ${ }^{[6]}$ as well as cation dependent. The (iso)cyanide bands are not present in the system containing $\mathrm{TBA}^{+} \mathrm{sa}^{-}$ turated with argon (see Figure 7, top panel), whereas in the presence of $\mathrm{Li}^{+}$and argon, only one of the bands that is attributed to the isocyanide stretching can be observed, but with a low intensity (see Figure 8, top panel). As mentioned, we ascribe the enhancement of these bands in both systems saturated with hydrogen to the removal of water from the interface by hydrogen oxidation.

Finally, Figure 9 shows the SER spectra in the region of 400$850 \mathrm{~cm}^{-1}$ for acetonitrile in the presence of TBAP and $50 \mathrm{~mm}$ of water. The spectra from 100 to $3500 \mathrm{~cm}^{-1}$ are shown as Figure $\mathrm{S} 4$ in the Supporting Information. In the top panel, we observe the formation of a broad band at high potentials of approximately $0.8-0.9 \mathrm{~V}_{\mathrm{SHE}}$ centered around $570 \mathrm{~cm}^{-1}$, reported ${ }^{[16]}$ as a mixture of $\mathrm{Pt}-\mathrm{O}$ and $\alpha-\mathrm{PtO}_{2}$. Again, this suggests that water is present at the Pt-acetonitrile interface, and it becomes oxidized at sufficiently positive potentials. However, the platinum-oxide band is not observed for the hydrogen-saturated solution, as shown in the bottom panel of Figure 9. This is 
$v-\mathrm{CN}, \mathrm{v}-\mathrm{CH}_{\mathrm{x}}$ region

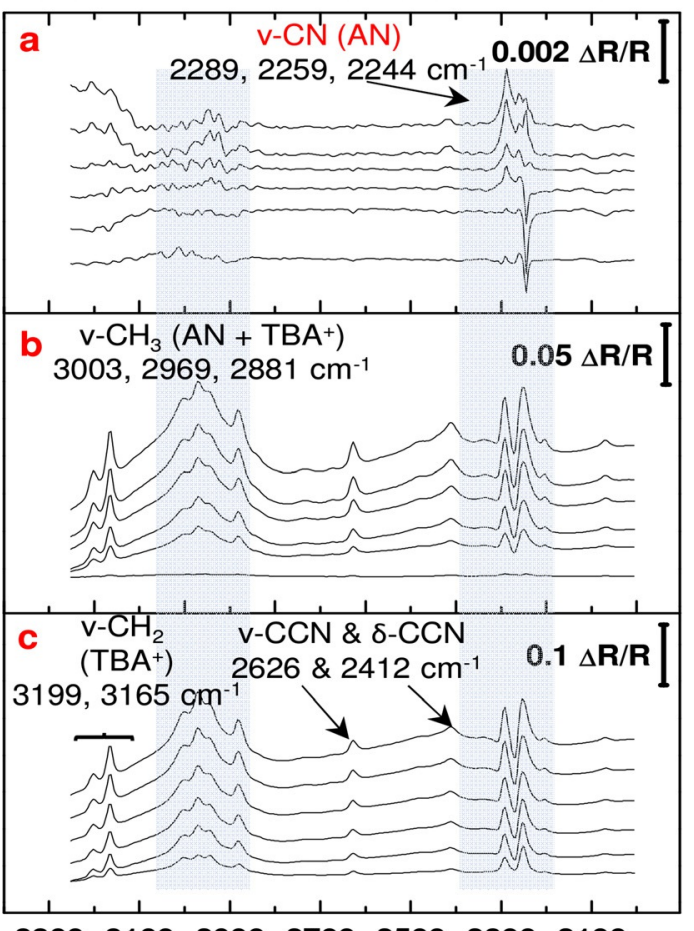

3300310029002700250023002100
3300310029002700250023002100

$\mathrm{v}$-Cl-O region

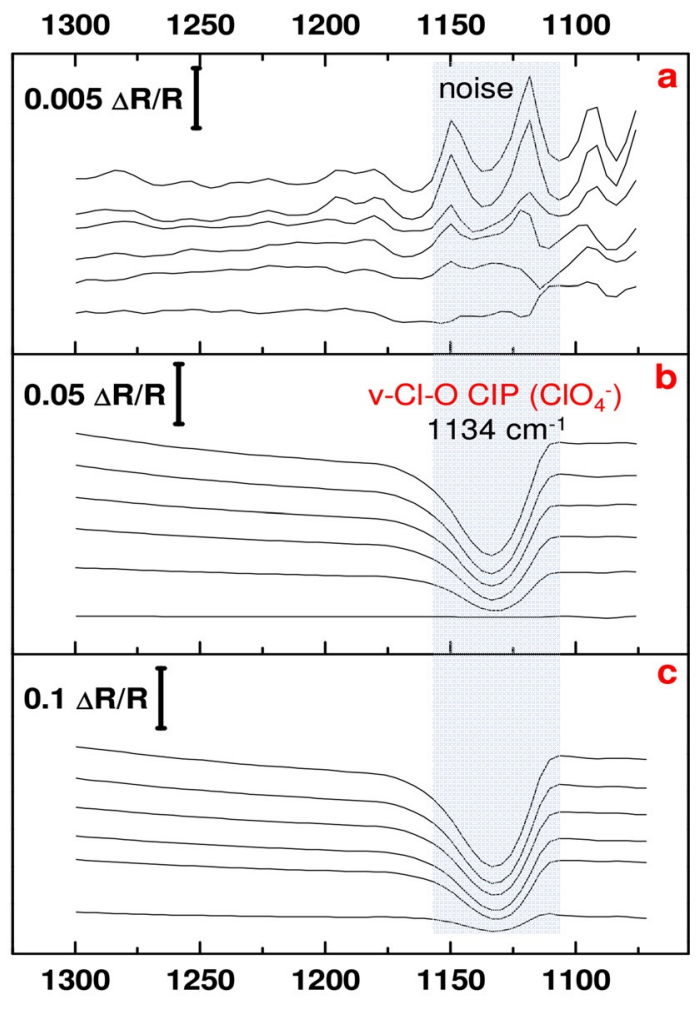

$\delta$-OH region

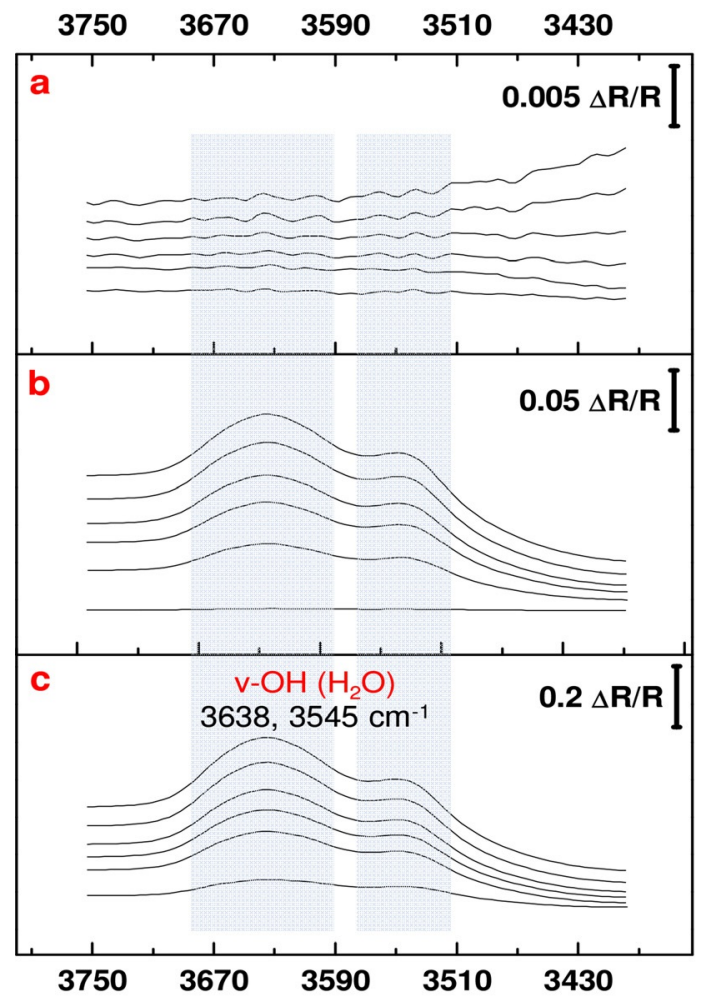

$\begin{array}{llllll}2000 & 1900 & 1800 & 1700 & 1600 & 1500\end{array}$
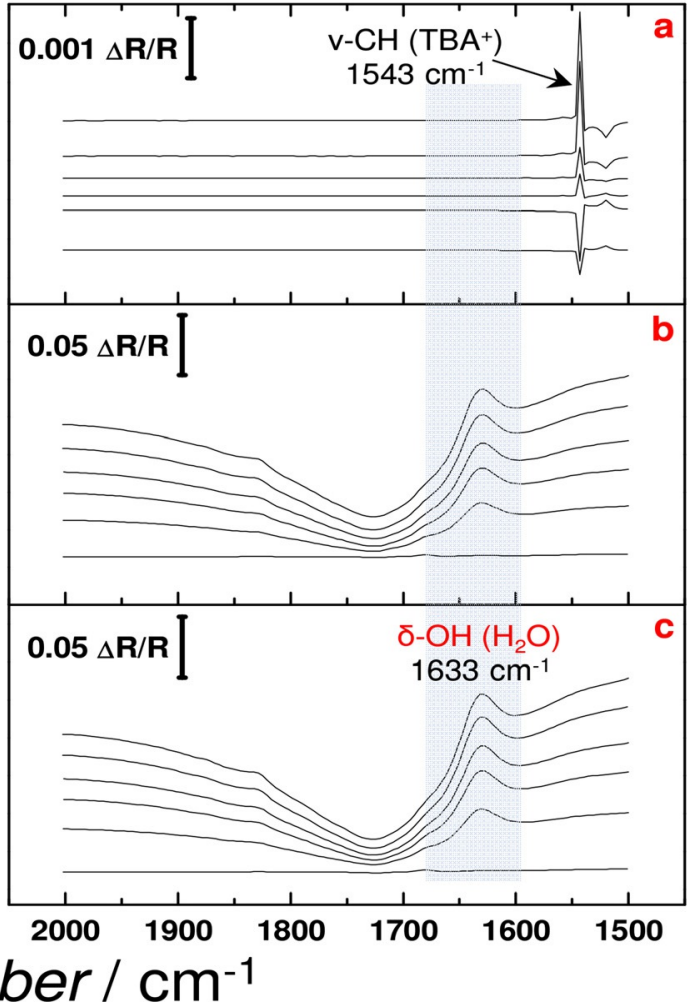

Figure 5. Potential-dependent SNIFTIR spectra for a polycrystalline platinum electrode in acetonitrile, containing $100 \mathrm{~mm}$ TBAP as the supporting electrolyte: a) argon atmosphere; b) hydrogen atmosphere; c) after adding $10 \mathrm{mM} \mathrm{HClO}_{4}$, under a hydrogen atmosphere. Reference spectrum: $-0.500 \mathrm{~V}_{\mathrm{Ag}}{ }^{0} \mathrm{Ag}^{+}$(corresponding to $\left.-0.314 \mathrm{~V}_{\mathrm{SHE}}\right)$. 
$\begin{array}{lllllll}3300 & 3100 & 2900 & 2700 & 2500 & 2300 & 2100\end{array}$

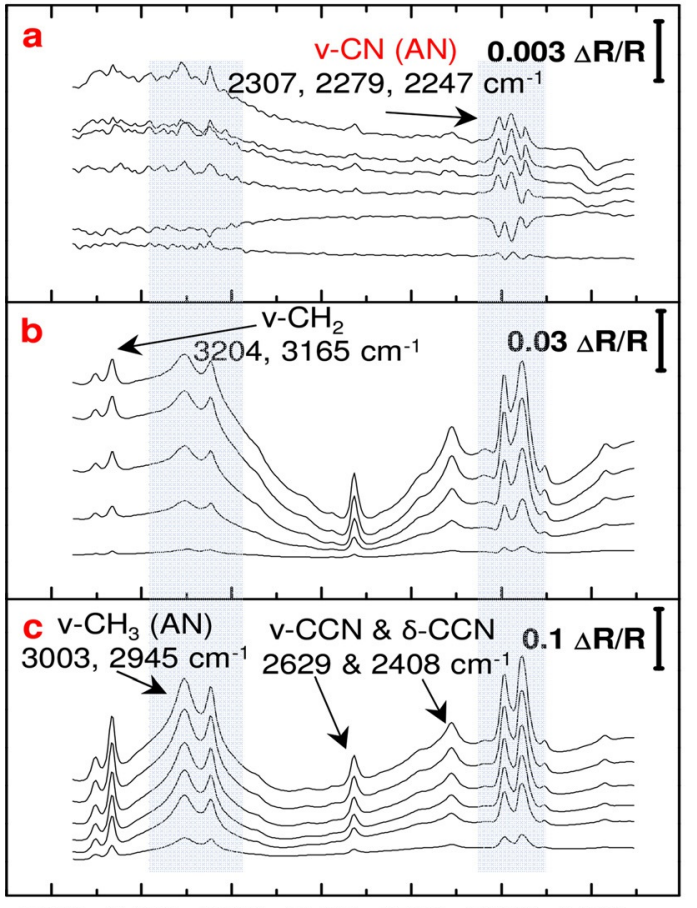

3300310029002700250023002100

\section{$v$-Cl-O region}

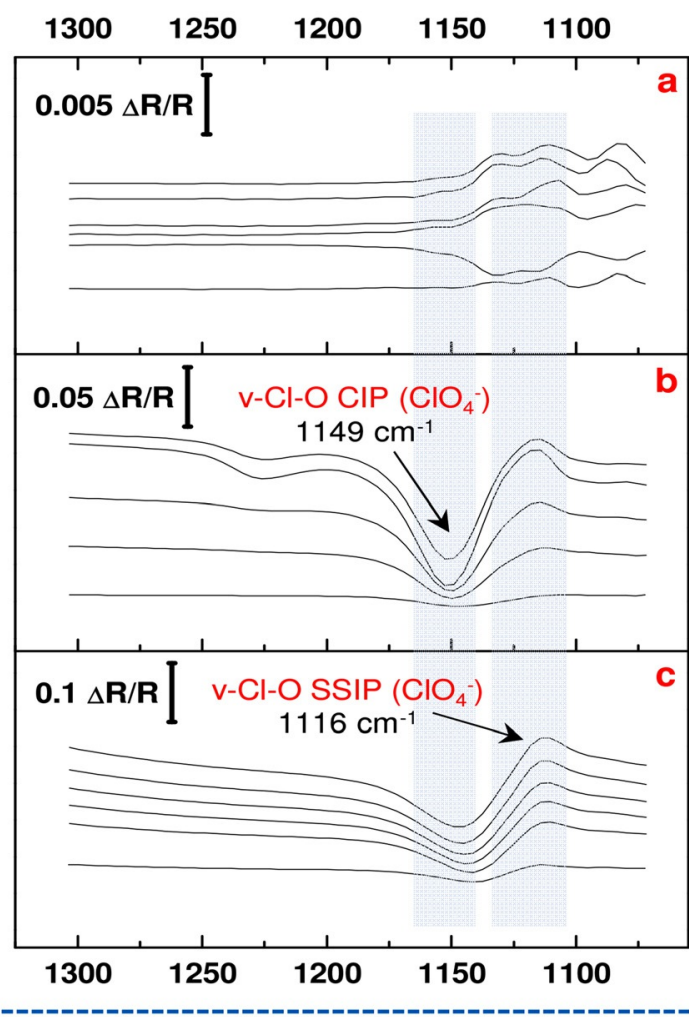

\section{$\delta$-OH region}

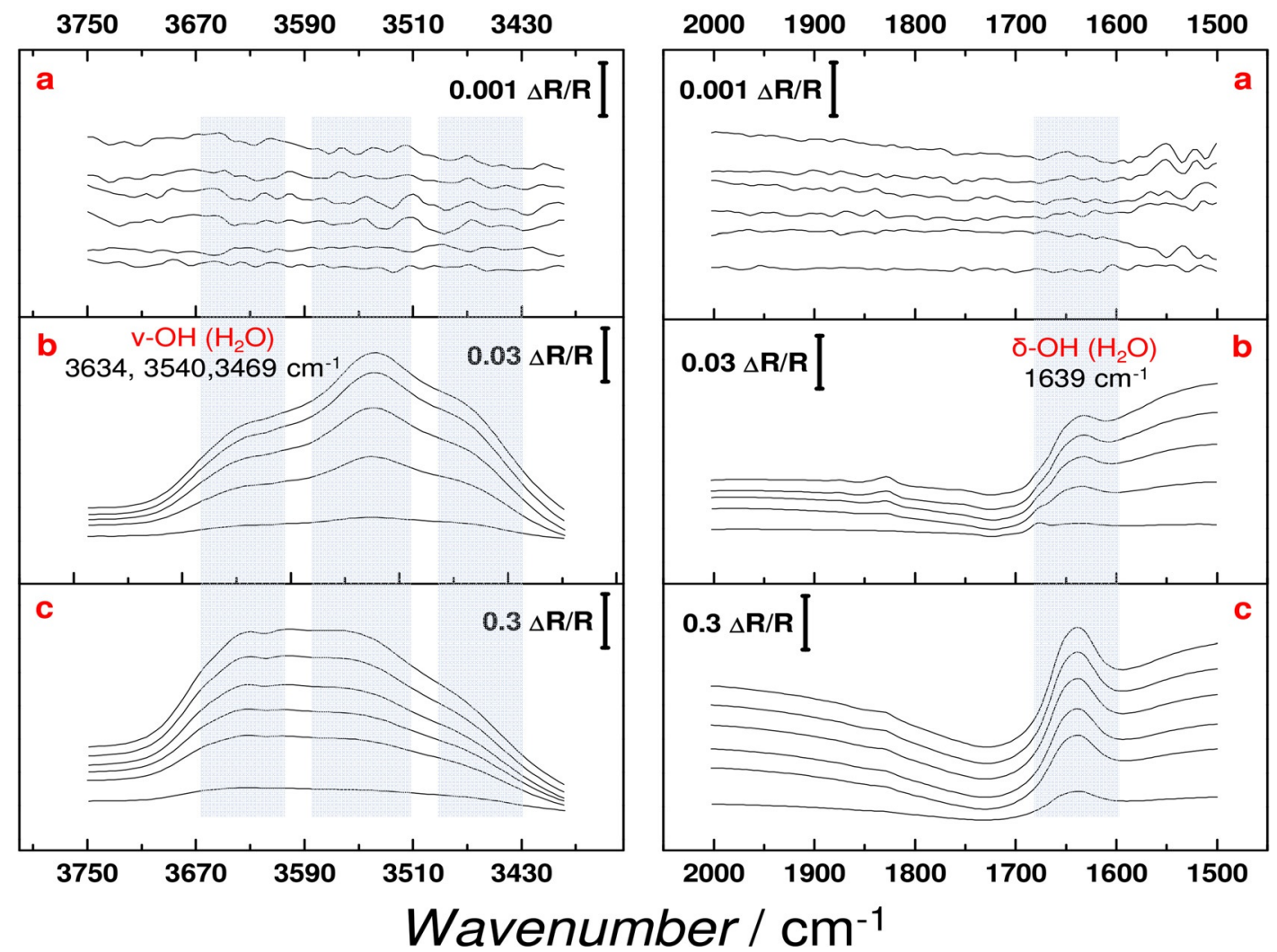

Figure 6. Potential-dependent SNIFTIR spectra for a polycrystalline platinum electrode in acetonitrile, containing $100 \mathrm{~mm} \mathrm{LiClO}_{4}$ as the supporting electrolyte: a) argon atmosphere; b) hydrogen atmosphere; c) after adding $10 \mathrm{mM} \mathrm{HClO}_{4}$, under a hydrogen atmosphere. Reference spectrum: $-0.500 \mathrm{~V}_{\mathrm{Ag}}{ }^{0}{ }_{\mathrm{Ag}}{ }^{+}$(corresponding to $-0.314 \mathrm{~V}_{\mathrm{SHE}}$ ). 


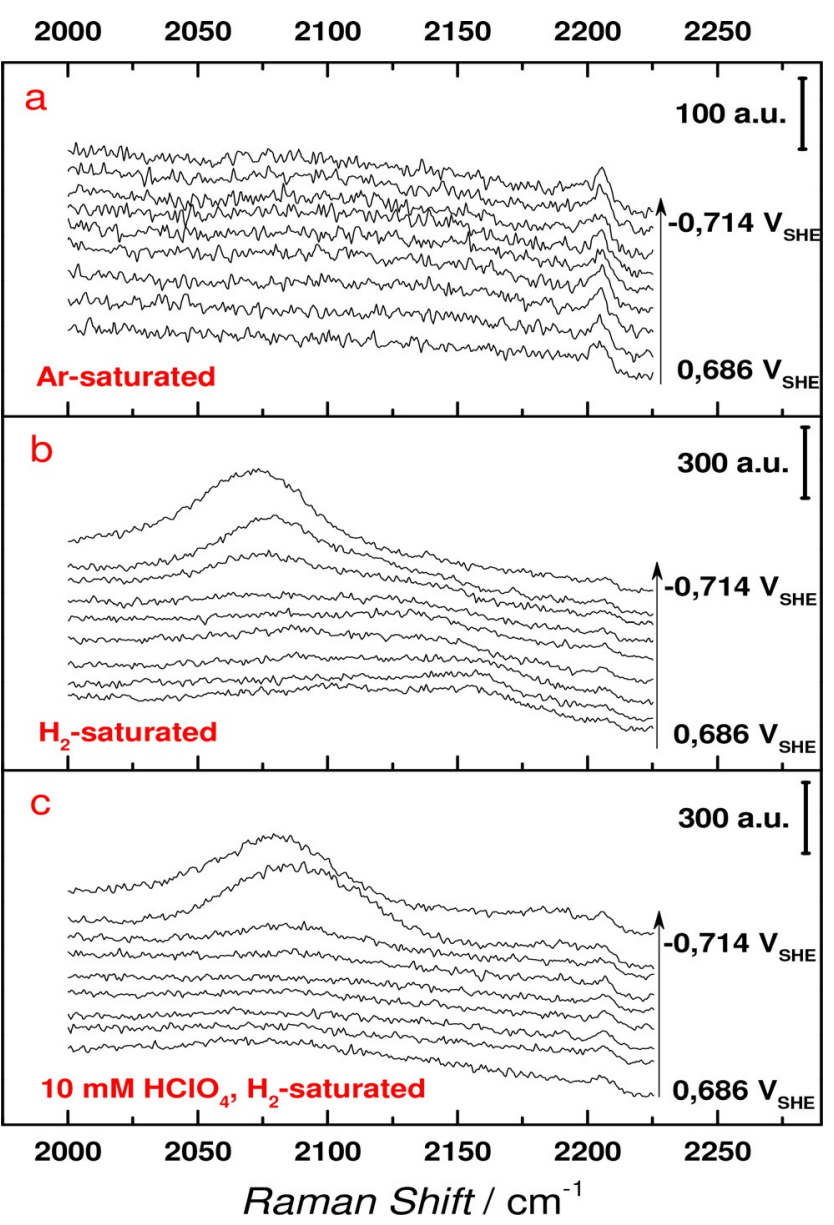

Figure 7. Potential-dependent SER spectra for acetonitrile, containing $100 \mathrm{~mm}$ TBAP as the supporting electrolyte: a) argon atmosphere; b) hydrogen atmosphere; c) after adding $10 \mathrm{~mm} \mathrm{HClO}_{4}$, hydrogen atmosphere.

consistent with our conclusion that water is removed from the interface under conditions of hydrogen oxidation. We note that these experiments were only performed in a solution containing TBAP as the supporting electrolyte, as $\mathrm{LiClO}_{4}$ forms visible aggregates on the electrode surface in presence of $50 \mathrm{~mm}$ of water, presumably because of the formation of $\mathrm{LiOH}^{\left[{ }^{[17]}\right.}$

\subsection{Discussion}

Our aim in this paper was to categorize and ultimately understand the differences and similarities in kinetics of the HOR/ HER in acetonitrile in the presence of two supporting electrolytes, with their main difference being the nature of the cation, that is, the tetrabutylammonium cation, as a hydrophobic/lipophilic cation, versus $\mathrm{Li}^{+}$as a metallic, hydrophilic cation. As our solutions contained trace amounts of water from different sources (primarily from the electrolyte and the acid), we purposefully added a controlled amount of water to evaluate its effect more clearly. Our results indicate the high sensitivity of the HOR/HER kinetics in acetonitrile towards the presence of even small amounts of water.

The voltammetry of HOR and HER in acetonitrile (Figure 1) shows that their kinetics are relatively insensitive to the nature

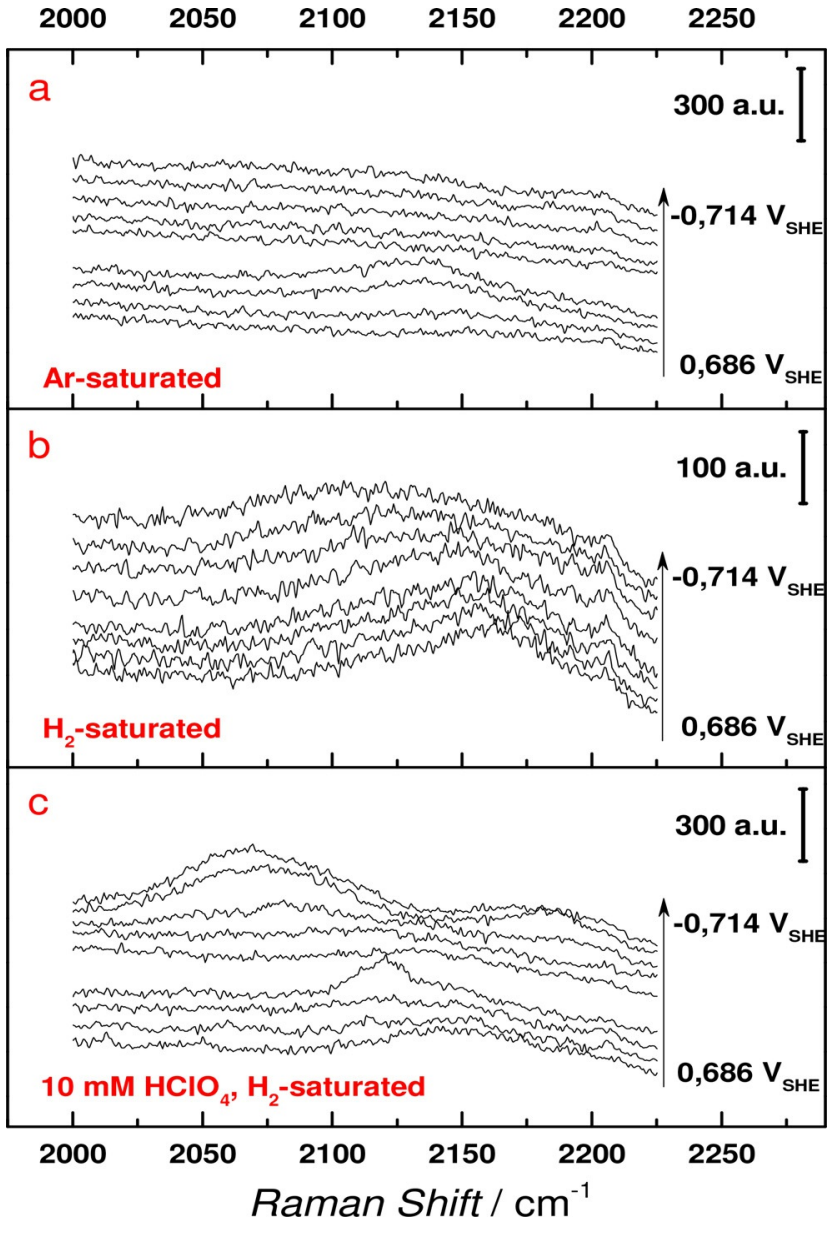

Figure 8. Potential-dependent SER spectra for acetonitrile, containing $100 \mathrm{~mm} \mathrm{LiClO}_{4}$ as the supporting electrolyte: a) argon atmosphere; b) hydro-

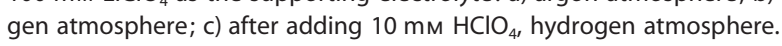

of the electrolyte cation. The reaction is reversible and the observed equilibrium potential corresponds well with the expected reversible potential. From the voltammetry, the addition of water (Figure 2) appears to have a limited influence, with the exception of a significant lowering of the HOR current in the $\mathrm{Li}^{+}$-containing electrolyte. It has been reported that $\mathrm{Li}^{+}$can associate with hydroxyl groups from water to form LiOH aggregates on the electrode surface, ${ }^{[17]}$ which can block the active sites for HOR/HER. Even though no visible aggregates were observed on the electrode surface in the absence of added water, we cannot discard its formation.

Both in situ FTIR and SERS experiments show that (a trace amount of) water plays a crucial role. These experiments suggest that water is present at the Pt-acetonitrile interface initially, but is not observable until the oxidation current is flowing, in the presence of molecular hydrogen. When $\mathrm{H}_{2}$ is oxidized, the protons generated are preferentially solvated by water molecules, and leave the interface by migration of the solvated protons. Simultaneously, perchlorate ions migrate towards the surface. The SER spectra showed that platinum oxides are only formed in presence of water, at high positive potentials, and their formation is suppressed under hydrogen oxidation conditions. 


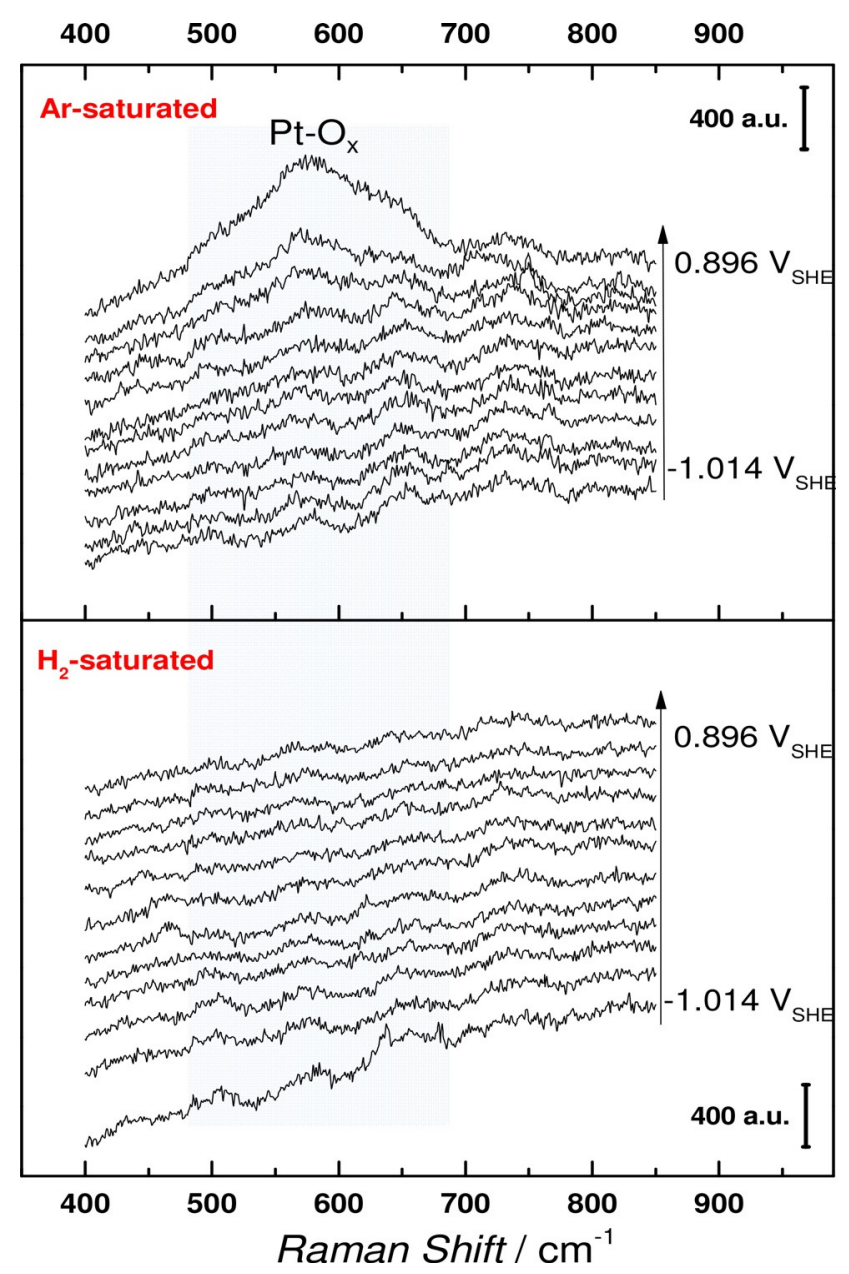

Figure 9. Potential-dependent SER spectra for acetonitrile, containing $100 \mathrm{~mm}$ TBAP as the supporting electrolyte, in the presence of $50 \mathrm{~mm}$ of water.

The preferential solvation of protons by water in acetonitrile, leading to the migration of water away from the electrode surface once the protons are generated, is in good agreement with earlier conclusions about protons in acetonitrile-water mixtures. The preferential solvation of protons by water in water-acetonitrile mixtures follows from thermodynamic studies. ${ }^{[15,18]}$ Sublemontier and co-workers ${ }^{[5]}$ studied protons surrounded by solvent shells, following the mass spectra of supersonic beams containing hydrogen-bonded clusters of acetonitrile and water molecules. Their results showed that the protons, in the presence of acetonitrile and small amounts of water, form solvation shells with the structure $\left(\mathrm{CH}_{3} \mathrm{CN}\right)_{n}\left(\mathrm{H}_{2} \mathrm{O}\right)_{n-2} \mathrm{H}^{+}$. Furthermore, the stability of these clusters is granted by the formation of hydrogen bonds, and the arrangement of acetonitrile molecules in the outer coordination sphere is related to the acetonitrile as an acceptor of hydrogen bonds. A study by Domain and Benoit ${ }^{[19]}$ reported the enthalpy of solvation of protons for several solvents, including water and acetonitrile. In their work, the heat of solvation for a proton in acetonitrile is $-251 \mathrm{kcal} \mathrm{mol}^{-1}$, whereas for water it is $-270 \mathrm{kcal} \mathrm{mol}^{-1}$. As stated by Burger, ${ }^{[20]}$ these findings correlate well with the Gutmann donicities of both solvents (i.e. their ability to solvate cations) and endorse our observations of preferential solvation.

Regarding the low HOR currents registered in presence of $\mathrm{Li}^{+}$(see Figure 1), we propose that the effect is related to the strong lithium-water interaction. Like protons, lithium is preferentially solvated by water in water-acetonitrile mixtures. ${ }^{[15]}$ Water is a source of hydroxyl species, whose formation is promoted by the presence of $\mathrm{Li}^{+} .^{[17]}$ As mentioned, in the presence of a larger amount of water in $\mathrm{LiClO}_{4}$, a deposit was observed on the electrode surface. On the other hand, it has been reported ${ }^{[21]}$ that the $\mathrm{TBA}^{+}$is solvated by acetonitrile; moreover, it can form hydrophobic clusters with the solvent, even at high water concentrations.

From our observations, we conclude that the hydrogen oxidation and evolution in acetonitrile are mediated by the presence of water, and this sensitivity towards the nature of the cations is attributed to preferential solvation effects. Therefore, we propose that the overall reaction of HOR/HER on platinum in acetonitrile should be written as [Eq. (3)]:

$\mathrm{H}_{2}+2 n \mathrm{H}_{2} \mathrm{O}(\mathrm{AN}) \leftrightarrow 2 \mathrm{H}^{+}\left(\mathrm{H}_{2} \mathrm{O}\right)_{n}(\mathrm{AN})+2 \mathrm{e}^{-}$

The detailed structure of the solvation shells for the cations is beyond the scope of this study. Like our present work, many previous reports on the HOR/HER on Pt in acetonitrile did not use rigorously water-free acetonitrile in combination with rigorously water-free electrolytes. In light of our results, the practical meaning of the hydrogen electrode as a potential reference or activity benchmark in acetonitrile has its limitations, because protons are preferentially solvated by water, at least under the experimental conditions described in this work. In general, the HOR/HER electrode kinetics in acetonitrile are highly sensitive to the presence of water traces, even to the extent that purposefully adding water makes no apparent difference.

\section{Conclusions}

We studied the hydrogen oxidation and hydrogen evolution reactions on a platinum electrode in an acetonitrile-based electrolyte, by using a combination of voltammetry and in situ FTIR and Raman spectroscopies. From these spectroelectrochemical measurements, in the absence and presence of added water, we conclude that the hydrogen oxidation and evolution in acetonitrile is strongly mediated by (trace amounts of) water, as the protons generated through hydrogen oxidation are preferentially solvated by water. These water-carrying protons migrate away from the electrode surface during the anodic reaction. Therefore, the reversibility of HOR/HER in acetonitrile depends, to a certain extent, on the solvation degree of the species involved in the electrocatalytic reaction, specifically on the presence of water. We also conclude that water is not involved in the electrochemical reaction, but it acts as a co-solvent to the cations in solution. This makes it difficult to establish a proper hydrogen reference electrode for nonaqueous solvents, and impacts on comparing catalysts of the HOR/HER reaction in different solvents. The im- 
plications of our conclusions could be extended to other systems under similar conditions, such as dimethylformamide and dimethylsulfoxide, which are also widely used in test systems for the development of new catalysts for hydrogen evolution.

\section{Experimental Section}

Solutions were prepared by using as-received acetonitrile (Anhydrous $99.8 \%$, from Sigma-Aldrich). As a proton source, we used perchloric acid (70\% Suprapur Merck). $\mathrm{LiClO}_{4}$ and tetrabutylammonium perchlorate for electrochemical analysis $(99.0 \%$ from SigmaAldrich) were used as supporting electrolytes. Ferrocenium hexafluorophosphate (97\%, from Sigma-Aldrich) and ferrocene (99\%, from Alfa Aesar) were used in equimolar concentration to calibrate the equilibrium potential of the $\mathrm{Ag} / \mathrm{AgClO}{ }_{4}$ reference electrode used in this work. All the solutions were purged with argon (purity grade 6.0), but for the experiments performed under a hydrogen atmosphere, we used a constant hydrogen flux (purity grade 5.6). No further attempts were made to dry the electrolyte solutions.

Prior to the experiments, the glassware was rinsed with water (Milipore MiliQ; resistivity $>18.2 \mathrm{M} \Omega \mathrm{cm}$ ) and then with acetone (Sigma-Aldrich), before being placed in an oven, overnight, at $120^{\circ} \mathrm{C}$.

For the electrochemical measurements, we used an Ivium potentiostat/galvanostat (IviumStat) connected to a one-compartment, three-electrode cell. The working electrode (WE) was a platinum wire with a diameter of $120 \mu \mathrm{m}$ and a real surface area of $(5.9 \pm$ $0.1) \times 10^{-4} \mathrm{~cm}^{2}$, as measured from hydrogen adsorption/desorption in aqueous solution, ${ }^{[22]}$ assembled to a glass stem and flame annealed before each measurement. The counter electrode (CE) consisted of a platinum spiral, whereas the reference electrode (RE) was a homemade $\mathrm{Ag} / \mathrm{AgClO}$ electrode in acetonitrile. The RE consisted of a silver wire immersed in a glass tube, filled with a $1 \mathrm{~mm}$ $\mathrm{Ag} / \mathrm{AgClO}_{4}$ solution in acetonitrile. The tube had a glass junction allowing the free transport of ions from the Luggin capillary into the electrolyte. A $10 \mu \mathrm{F}$ capacitor was connected, as a noise filter, between the RE and a platinum wire immersed in the solution. To calibrate "zero" in the $\mathrm{Ag} / \mathrm{AgClO}_{4} \mathrm{RE}$ scale with respect to the SHE scale, we prepared a ferrocene/ferrocenium solution in an equimolar concentration $(10 \mathrm{~mm})$, as the accepted internal standard for electrochemical measurements in nonaqueous solutions, and measured its cyclic voltammetry against the $\mathrm{Ag} / \mathrm{AgClO}_{4} \mathrm{RE}$. The equilibrium potential of the redox couple $\mathrm{Fc}^{0} / \mathrm{Fc}^{+}$was calculated as the half-wave potential in the cyclic voltammetry, and the measured value was $0.038 \mathrm{~V}$.

SERS measurements were performed with a confocal Raman microscope (LabRam HR, Horiba Yobin Yvon), equipped with a $\mathrm{He} / \mathrm{Ne}$ laser $(633 \mathrm{~nm})$ and a $50 \times$ objective. The electrochemical measurements were controlled with a Metrohm $\mu$ Autolablll potentiostat/ galvanostat, using an electrochemical cell with one compartment and three electrodes: a platinum wire $\mathrm{CE}, \mathrm{Ag} / \mathrm{AgClO}_{4}$ in acetonitrile $\mathrm{RE}$, and the WE consisted of $2 \mathrm{ML}$ of platinum deposited galvanostatically from an aqueous $100 \mathrm{~mm}_{2} \mathrm{PtCl}_{6}$ solution on a roughened gold surface. ${ }^{[23]}$ The gold surface was previously polished with alumina (with different mesh sizes: 1, 0.3, and $0.05 \mu \mathrm{m}$ ), rinsed with ultrapure water, and sonicated for $10 \mathrm{~min}$ to remove any alumina residues remaining. The roughening procedure has been reported in the literature ${ }^{[24]}$ and involves immersing the electrode in a $100 \mathrm{~mm} \mathrm{KCl}$ solution and performing 25 oxidation-reduction cycles between -0.30 and $1.20 \mathrm{~V}$ versus SCE, by holding the cathodic potential for $30 \mathrm{~s}$ and the anodic potential for $1.3 \mathrm{~s}$.
The FTIR spectroscopy measurements were carried out in a threeelectrode cell coupled to a $\mathrm{CaF}_{2}$ prism slanted at $60^{\circ}$, and connected to a Bruker Vertex80V IR spectrophotometer. The WE was a platinum disc settled in a thin-layer configuration, the CE was a platinum wire, and the $\mathrm{RE}$ was $\mathrm{Ag} / \mathrm{AgClO}_{4}$ in acetonitrile. A total of 100 interferograms were averaged for each spectrum, with a resolution of $8 \mathrm{~cm}^{-1}$, as well as for the measurement of the transmission spectra, whereby the reference spectrum was taken from pure acetonitrile. The spectra in this work were reported as difference spectra with respect to a background spectrum, and normalized against such reference, $\left(T-T_{0}\right) / T_{0}$, where $T$ is the recorded spectrum and $T_{0}$ is the background spectrum. Hence, bands pointing upwards correspond to the depletion of species at the electrode surface and were called positive bands, whereas bands pointing downwards indicate the adsorption of species and were assigned as negative bands.

\section{Acknowledgements}

This work was supported by the Netherlands Organization for Scientific Research (NWO) through a TOP grant awarded to M.T.M.K., and in part by the BioSolar Cells Open Innovation Consortium, supported by the Dutch Ministry of Economic Affairs.

Keywords: hydrogen - platinum - redox reactions - solvent effects $\cdot$ vibrational spectroscopy

[1] a) D. Strmcnik, M. Uchimura, C. Wang, R. Subbaraman, N. Danilovic, V. van der, A. P. Paulikas, V. R. Stamenkovic, N. M. Markovic, Nat. Chem. 2013, 5, 300-306; b) R. Subbaraman, D. Tripkovic, D. Strmcnik, K.-C. Chang, M. Uchimura, A. P. Paulikas, V. Stamenkovic, N. M. Markovic, Science 2011, 334, 1256-1260; c) N. Hoshi, Y. Asaumi, M. Nakamura, K. Mikita, R. Kajiwara, J. Phys. Chem. C 2009, 113, 16843-16846; d) K. S. Juodkazis, J. Juodkazytè, B. Šebeka, S. Juodkazis, Appl. Surf. Sci. 2014 290, 13-17; e) K. Kunimatsu, T. Senzaki, G. Samjeské, M. Tsushima, M. Osawa, Electrochim. Acta 2007, 52, 5715-5724; f) J. A. Lanning, J. Q. Chambers, Anal. Chem. 1973, 45, 1010-1016; g) M. M. Roubelakis, D. K. Bediako, D. K. Dogutan, D. G. Nocera, Energy Environ. Sci. 2012, 5, 7737-7740; h) T. J. Schmidt, P. N. Ross Jr, N. M. Markovic, J. Electroanal. Chem. 2002, 524-525, 252-260.

[2] a) R. Angamuthu, E. Bouwman, Phys. Chem. Chem. Phys. 2009, 11, $5578-$ 5583; b) C. Baffert, V. Artero, M. Fontecave, Inorg. Chem. 2007, 46, 1817-1824; c) G. A. N. Felton, R. S. Glass, D. L. Lichtenberger, D. H. Evans, Inorg. Chem. 2006, 45, $9181-9184$; d) V. Fourmond, P. A. Jacques, M. Fontecave, V. Artero, Inorg. Chem. 2010, 49, 10338-10347; e) M. L. Helm, M. P. Stewart, R. M. Bullock, M. R. DuBois, D. L. DuBois, Science 2011, 333, 863-866; f) C. H. Lee, D. K. Dogutan, D. G. Nocera, J. Am. Chem. Soc. 2011, 133, 8775-8777; g) J. A. S. Roberts, R. M. Bullock, Inorg. Chem. 2013, 52, 3823-3835; h) C. N. Valdez, J. L. Dempsey, B. S. Brunschwig, J. R. Winkler, H. B. Gray, Proc. Natl. Acad. Sci. USA 2012, 109, $15589-15593$.

[3] a) B. D. McCarthy, D. J. Martin, E. S. Rountree, A. C. Ullman, J. L. Dempsey, Inorg. Chem. 2014, 53, 8350-8361; b) A. V. Rudnev, E. B. Molodkina, A. I. Danilov, Y. M. Polukarov, A. Berna, J. M. Feliu, Electrochim. Acta 2009, 54, 3692-3699; c) M. F. Suárez-Herrera, M. Costa-Figueiredo, J. M. Feliu, Langmuir 2012, 28, 5286-5294; d) M. Szklarczyk, J. Sobkowski, Electrochim. Acta 1980, 25, 1597-1601; e) J. Zieja, J. Gadomska-Trzos, Z. Stojek, Electroanalysis 2001, 13,621-625.

[4] a) J. Klunker, W. Schäfer, J. Electroanal. Chem. 1999, 466, 107-116; b) A Kütt, I. Leito, I. Kaljurand, L. Sooväli, V. M. Vlasov, L. M. Yagupolskii, I. A. Koppel, J. Org. Chem. 2006, 71, 2829-2838; c) W. Lv, R. Zhang, P. Gao C. Gong, L. Lei, J. Solid State Electrochem. 2013, 17, 2789-2794; d) V. V. Pavlishchuk, A. W. Addison, Inorg. Chim. Acta 2000, 298, 97-102; e) S. Wasmus, E. Cattaneo, W. Vielstich, Electrochim. Acta 1990, 35, $771-775$. 
[5] a) J. Barthel, R. Buchner, E. Wismeth, J. Solution Chem. 2000, 29, $937-$ 954; b) P. Eberspächer, E. Wismeth, R. Buchner, J. Barthel, J. Mol. Liq 2006, 129, 3-12; c) J. M. Mestdagh, A. Binet, O. Sublemontier, J. Phys. Chem. 1989, 93, 8300-8303; d) Y. Marcus, G. Hefter, Chem. Rev. 2006, $106,4585-4621$.

[6] R. A. Gu, P. G. Cao, Y. H. Sun, Z. Q. Tian, J. Electroanal. Chem. 2002, 528, $121-126$.

[7] W. C. Barrette, D. T. Sawyer, Anal. Chem. 1984, 56, 653-657.

[8] D. Strmcnik, D. Tripkovic, D. van der Vliet, V. Stamenkovic, N. M. Marković, Electrochem. Commun. 2008, 10, 1602-1605.

[9] A. Markovits, C. Minot, Catal. Lett. 2003, 91, 225-234.

[10] K. Izutsu, Acid-Base Dissociation Constants in Dipolar Aprotic Solvents, Blackwell Science, Oxford, 1990.

[11] W. R. Fawcett, Langmuir 2008, 24, 9868-9875.

[12] H. Angerstein-Kozlowska, B. Macdougall, B. E. Conway, J. Electroanal. Chem. Interfacial Electrochem. 1972, 39, 287-313.

[13] a) J. Barthel, R. Deser, J. Solution Chem. 1994, 23, 1133-1146; b) W. R. Fawcett, M. Fedurco, M. Opallo, J. Phys. Chem. 1992, 96, 9959-9964; c) J. S. Loring, W. R. Fawcett, J. Phys. Chem. A 1999, 103, 3608-3617.

[14] N. Kizhakevariam, I. Villegas, M. J. Weaver, Surf. Sci. 1995, 336, 37-54.

[15] Y. Marcus, lon solvation, Wiley, Chichester, New York, 1985.
[16] a) S. Zou, H. Y. H. Chan, C. T. Williams, M. J. Weaver, Langmuir 2000, 16, 754-763; b) H. Y. H. Chan, S. Zou, M. J. Weaver, J. Phys. Chem. B 1999, 103, $11141-11151$; c) H. Luo, S. Park, H. Y. H. Chan, M. J. Weaver, J. Phys. Chem. B 2000, 104, 8250-8258.

[17] L. G. Irr, Electrochim. Acta 1984, 29, 1-5.

[18] G. Hefter, Pure and Applied Chemistry 2005, 77, 605-617.

[19] R. Domain, M. Benoit, Can. J. Chem. Revue Canadienne De Chimie 1976, 54, 2101-2109.

[20] K. Burger, Solvation, lonic and Complex Formation Reactions in NonAqueous Solvents, Elsevier, Amsterdam, Oxford, 1983.

[21] G. Saielli, G. Scorrano, A. Bagno, A. Wakisaka, ChemPhysChem 2005, 6, $1307-1315$.

[22] S. Trasatti, O. A. Petrii, J. Electroanal. Chem. 1992, 327, 353-376.

[23] S. Zou, M. J. Weaver, Anal. Chem. 1998, 70, 2387-2395.

[24] P. Gao, D. Gosztola, L.-W. H. Leung, M. J. Weaver, J. Electroanal. Chem. Interfacial Electrochem. 1987, 233, $211-222$.

Manuscript received: August 7, 2015

Accepted Article published: September 9, 2015

Final Article published: September 21, 2015 